\title{
Guidelines to Reduce Traffic Accident Rate of Migrant Workers in Sansai District, Chiangmai Province Thailand
}

\author{
Patcharaphong Akarametagul \\ School of Administrative Studies, Maejo University, Chiangmai, Thailand \\ Corresponding author: dr.patcharaphong59@gmail.com
}

\begin{abstract}
This research study guide lines to reduce traffic accident of migrant works in Sansai district, Chiangmai province. The research model and its development were combine through qualitative and quantitative research. Using structural interview method and data were analyze with content analysis. The result of this research works shows that the nature and causes of migrant workers road accidents were driving habits, both in terms of carelessness and not knowing traffic rules and regulation including traffic light and warning signs. This kind of driving behavior of migrant workers has been a long time problem that resulted to the loos and damage of life and property. Management Process in case of road accidents involving migrant workers shows that in situation were cases needs to be reported or sued according to the law; they are notified within 1-3 hours after the accident. However, the guidelines for managing road traffic accidents involving migrant workers warrant that there should be law enforcement and the creation of community service and this research work will be a guideline for creating valuable knowledge and help in change the driving behavior of migrant workers.
\end{abstract}

Keywords-management guidelines, road accident, migrant workers, content analysis

\section{INTRODUCTION}

The development of Thailand current economic has encountered rapid growth; this can be explicitly seen with the structural changes that is going on in the labour market. The production structure, meant for domestic consumption in the past, has now been overturned for exportation, including the replacement of importation. Therefore, this dramatically has an effect on the industrial and service sector to acquire more labour in production process. On the contrary, Thailand labour market reject the usage of Thai laborer in the production process, with the excuse that they are laborer with risk, dirty, and inconvenient. As a result cause a shortage in the production process allowing entrepreneurs pay more attention to migrant workers because of their low wages cost if compared to Thailand laborer, because they are industrious and patient. However, these migrant workers sees that coming to work in Thailand give them more opportunity to have an increased and large amount of income if compared to their respective countries. Therefore leading to the smuggling of migrant workers from neighboring countries such as; Myanmar, Lao and Cambodia. The employment of these migrant workers, the employee must also follow and practice according to the law.
According to the situation of migrant workers surveyed on August 31, 2015 by [6]. Which they provide the information in January 2016, saying that there are 1,470,225 migrant workers authorized to work throughout the Kingdom. Which are from Myanmar, Lao and Cambodia according to the statistics they are migrant workers that came to Thailand legally, illegal migrant workers are not included, which also include a large amount of individuals and there are tendencies of continuous increase. The coming of migrant workers to Thailand, push them to adapt themselves with the way of life in the new social system they find themselves such as social and other related laws. The driving behavior of migrant works in the past can be explicitly seen that is always result to fatal accidents and the causes of these accidents can be from various factors such as; not knowing traffic rules, health status, negligence, addicted to the traffic rules of their respective countries, condition of their vehicles. The physical characteristics of the road, which is one of the issue the researcher is interested on, thereby studying the characteristics of the accidents, which occur.

For Thailand, World Health Organization (WHO) estimates that Thailand's road accident deaths are second to Namibia with 36.2 deaths per 100,000 population in 2014 . There are 3 out of 4 people involved in accident used motorcycles i.e. $76 \%$ ( 857,572 people) followed by bicycles $8 \%$ (99,298 people) and pedestrians [5].

As for Chiang Mai province, the amount of road accidents are quite much as well, [4] classified the causes of these accidents in 2015 as follows; Caused by individuals, such as 1,165 people get drunk with alcohol, narcotics and negligence, 930 people were involved in accidents caused by the environment, such as road damage, narrow roads, rain, no signs or traffic lights. 797 people were involved in accidents caused by driving equipment such as steering system failure, damaged safety equipment and crashed tires, the aforementioned accident statistics are considered quite large numbers in Chiang Mai. These statistics also include victims who are (migrant workers) are also included in this statistics.

For this reason, therefore serves as a urge for the research to be interested on the characteristics of accident that occur on the road involving migrant workers, in order to identify the causes or factors responsible for the accident of migrant workers. Thereby, introduce a management approach in reducing the rate of road accident of migrant workers in San 
Sai district. The researcher chooses San Sai district, Chiang province because it houses a large amount of migrant workers, most especially construction workers migrants, where most of them transit from their various apartment in San Sai district to work in neighboring district.

\section{RESEARCH METHOD}

The model of this study is research and development, using qualitative research method mixed together with quantitative research method. Respondent used in qualitative research method were respondent who are shop owners, migrant workers and road safety officers total of 30 people. Respondent used in the Quantitative research method were; 119 case of road accidents involving migrant workers in Sansai District Chiang Mai province during the year 2014-2017. Five cases of specific respondents.

Research tools in gathering data in this research are divided according to research methodology as follows; Qualitative methods make use of structural interview, while recorder were used in collecting data for quantitative method.

The researcher-divided data analyzes according to the research methods as follows; Qualitative data: The researcher uses the content analysis method by gathering related research works, interview and present them by descriptive analysis.

Analysis of data from interview: The researcher gathered his data and conducts his analyzes using content analysis. Consideration of retrieved data were done by analyzing through the following steps; Gather retrieved data from interview, while the interview issues are; Guideline Management to reduce road accidents of migrant workers in Sansai district. Try to understand the retrieved data that are related to the research scope. Make a discussion guideline management in order to reduce rates of road accident involving migrant workers in Sansai district.

Quantitative data: Has the following analyzing steps; Data retrieved from recorded cases are analyze through quantitative method, the researcher check the accuracy of recorded cases, completeness and clarification. After then proceeds to the recording of data into the data file in order to prepare data for analysis and evaluation through computer program. Statistics used in data analysis: The researcher uses statistical baseline.

\section{RESUlT AND DISCUSSION}

Statistics of Road traffic accidents for migrant workers between 2014 and 2016 (as of May 2017). The researcher collects accident occurrence data at Sansai Police Station and Maejo Police the result shows that there are 538 cases of accidents in Sansai and 119 cases were accident that happened to migrant workers.

The result of studying of characteristic and the cause of road accidents of migrant workers a total of 119 cases it shows that, most of the accused were male between the age of 25-40 years. This was in accordance with department of employment [1] which says, workers that are below the age of 18 years are not allowed to work, except if the job is another because the said age are free of work. That was why in the research age 25
- 40 came in to work in a large quantity and most of them are Myanmar workers. This also went in accord with office of migrant worker administration [6]. From the statistic of workers that travel into Thailand, most of them are Myanmar workers; they came in so they can work as a maid, construction worker, waiter, farmers, fishery [7] said most Myanmar migrant workers focus more on working and gathering income in order to make a living for themselves. Most of the time accident occurred is when they are on their way back home from work, which is between 6 am - $6 \mathrm{pm}$. Moreover, it was discovered that the road environment is not main factor for the causes of accident. However, the main causes of accidents are from individual driving habits, both in terms of carelessness and not knowing the traffic laws, or warning signs and light. In terms of place where most accident occurred are often U-turn and straight roads etc. that is however in accordance with [3] Where he discovered that factor that influence the total number of accidents are: amount of traffic equipment on highway, factors that influence accident where people are injured are: amount of traffic in main road and its environs. Factors that influence accident where there may be dead people includes; amount of traffic on main roads, design speed, main road width, connecting roads, left and right traffic lanes. Because the main road is a straight lane with U-turn and it is a lane where high-speed vehicle pass by. Therefore, reckless driving and backward facing the car directly allow the cause for accident on a frequent basis, and most of the loos that occurred are injuries and loss of property.

In terms of management process in a situation where migrant workers are involved in an accident, the official inspect the victims if their stay in the kingdom is legitimate, has a passports and identity cards or not. Prosecution are according to the laws of road traffic accidents. Which are in accordance with [8] discussed police behaviour that is, police officers that deal with accused migrant workers and its result was in a quite good level, which is in accordance human rights principles. In terms of $\mathrm{n}$ within 1-3 hours after the incident and if a situation where they can agree on certain terms and condition, they will be fined and have to pay a compensation fee for the damages and the case will also end within 1-3 hours. In a case where agreement terms cannot be meet e.g. the car of the person involved in the accident was badly damaged, the accused cannot pay a compensation fee, the officer will keep the car at the police station till the end of the case.

Studying guidelines for managing road traffic accidents involving migrant workers in Sansai should have an enforced law and the creation of community service. For example, train and implement driving knowledge to migrant workers, together with CSR activities for the society or the creation of community service. The training process will effective in helping to solve the problem of road accidents involving migrant workers in San Sai sustainably. This is direct in line with National Business Editorial Staff [2] Saying that using Social Responsibility It is an important step in helping the to create a conscious mind in the Thai society. The abovementioned migrant worker are considered part of the society. Allowing such workers to be aware, he/she is part of the society. It is a sense of social responsibility. The training should include the following knowledge; Traffic law / 
regulation, warning signs /traffic light/different symbols that are been used as warning on the road. Knowledge pertaining to driving preparation (person / car), what should be done incase an accident occur such as; emergency call. Knowledge about punishments related to road accident cases and also penalties / dangers of in terms of Violations and Negligence.

\section{CONCLUSION}

Additional suggestion and idea from interview are as follows; however, the occurrence accident is a problem that related agencies including the community have always help in trying to solve. Both infrastructure, warning signs and the installation of CCTV cameras at various danger spots help in the reduction of accident. However, in terms of enough accident rate for migrant workers, the main factor apart for individual careless and lack of knowledge about traffic regulations, the only way to direct get access to these migrant workers and also educate them. This will be a sustainable way or method of solving the problem.

\section{REFERENCES}

[1] Chiang Mai Employment Office, "Number of Myanmar migrant workers applying for Work permission for the year 2015," Chiang Mai: Chiang Mai Employment Office 2017.

[2] Editorial office CSR, "New Business Management Power," Bangkok Matichon Publications 2007.

[3] E. Jinthawong, "Accident models for three - legged intersection on twolane rural highways," Thesis Master of Engineering. Graduate School Chiangmai University 2004.

[4] National Statistical Office, Land traffic accident," Retrieved on February 28, 2017, from Http://service.nso.go.th/nso/web/statseries/statseries21.html

[5] Office of Health Promotion Fund, "Thailand Road Accident Situation Report 2012-2013,” Bangkok: Office of Health Promotion Fund. 2016

[6] Office of Migrant Workers Administration Department of Employment, "Factsheet for Myanmar migrant workers. Laos and Cambodia Working in Thailand," Bangkok: Department of Employment 2017.

[7] S. Kongmol, "Problem and Impacts of Burmese migrant workers in Sansai District Chiangmai Province," e-thesis Master of Arts Program in Public Administration. Chiangmai University. 2013.

[8] S. Awpituk, "The legal procedure towards accused Burmese migrants according to the U.N. Human Rights Declaration: A case study of Phupingrajanivej Police Station, Mueang Chiang Mai District," Independent Study Master of Arts Program in Public Administration. Chiangmai University. 2012. 